ANUARIO MUSICAL, N. ${ }^{\circ} 61$

enero-diciembre 2006, 263-272

ISSN: $0211-3538$

\title{
VÍNCULOS ESTÉTICOS ENTRE MIGUEL QUEROL Y JOAN MARAGALL EN EL CANT ESPIRITUAL
}

\author{
Aurèlia PESSARRODONA I PÉREZ
}

\section{Resumen}

Miguel Querol es conocido sobre todo como musicólogo, pero uno de los temas que más le interesó fue la filosofía y, en concreto, el pensamiento estético y musical. En este aspecto, Querol sintió especial predilección por Joan Maragall, sobre quien hizo diversos artículos y del que musicó algunos poemas, entre los cuales destaca el Cant espiritual. En este trabajo, a partir del análisis y la comparación entre los postulados estéticos de Querol y Maragall y los recursos musicales del Cant espiritual, se estudia cómo esta pieza sintetiza el pensamiento y estilo de ambos autores, convirtiéndose en una reflexión sobre el arte, la capacidad creativa del hombre y el ser humano en sí.

\begin{abstract}
Miguel Querol is mainly known as musicologist, although he was deeply interested in Philosophy and, specifically, in aesthetics and music thought. In this field, he wrote several articles on Joan Maragall, one of his favourite poets, besides vocal music based on texts by him, noteworthy the Cant espiritual. In this work we study how the latter piece synthesizes the style and thinking of both artists, becoming a reflection on art, creativity and the human being. Our approach is based on the analysis and comparison between the aesthetic postulates adopted by Querol and Maragall and the musical resources of Cant espiritual.
\end{abstract}

Si bien es cierto que Miguel Querol es conocido sobre todo como investigador en el ámbito de la musicología histórica, uno de los temas que más le interesó fue la filosofía y, en concreto, el pensamiento estético y musical. En este aspecto, un personaje por el que Querol sintió especial predilección fue el poeta Joan Maragall2 ${ }^{2}$, sobre quien hizo diversos artículos y del que musicó algunos poemas, entre los cuales destaca el Cant espiritual. Mi propósito es, pues, desentrañar los posibles vín-

1. Este trabajo ha sido realizado gracias a una beca predoctoral para Formación de Personal Investigador de la Generalitat de Cataluña dentro del proyecto coordinado del Ministerio de Ciencia y Tecnología (BHA2002-04446-CO2-01) La práctica musical en la antigua Corona de Aragón en los siglos XVII-XIX. Vías para la recuperación del patrimonio musical histórico. 01: Cataluña y Valencia (Universidad Autónoma de Barcelona), del que es Investigador Principal el Dr. F. Bonastre.

2. Miguel QUEROL dedicó diversas publicaciones al pensamiento estético y musical de Joan Maragall. De entrada, le dedicó un capítulo en su tesis doctoral La escuela estética catalana contemporánea, publicada en Madrid; Consejo Superior de Investigaciones Científicas, Instituto "Diego Velázquez", 1953. La parte dedicada al pensamiento estético de Maragall apareció publicada a su vez en la Revista de ideas estéticas, 42 (1953), pp. 137-172, bajo el título "La estética de Maragall”. En este trabajo usaré como referencia este segundo artículo. Por otra parte, años más tarde QuERoL publicó el artículo "La estética musical de Juan Maragall (1860-1911)", en Anuario Musical, XV (1960), pp. 166-177. 
culos estéticos entre Joan Maragall y Miguel Querol a partir de esta obra, contrastándolos con sus artículos sobre el pensamiento de este poeta ${ }^{3}$.

\section{El Cant espiritual}

El Cant espiritual de Querol, "poema musical para cuatro voces mixtas"4, fue compuesto entre los años 1947 y $1951^{5}$. Precisamente en 1948 Querol se doctoró en Filosofía y Letras por la Universidad de Madrid con su tesis La escuela estética catalana contemporánea, en la cual incluye, en el capítulo dedicado al pensamiento estético de Joan Maragall, un análisis pormenorizado del Cant espiritual por considerarlo la "síntesis de las doctrinas maragallianas"6. Así pues, durante la composición de esta obra, Querol tenía bien presente todo el pensamiento tanto estético como metafísico de este poema.

El tema de la obra puede enunciarse como la experiencia estética causada por la contemplación del mundo a través de los sentidos y el conflicto del poeta entre esta experiencia de raíz sensitiva y su fe cristiana ${ }^{7}$. En efecto, el poema resulta una verdadera síntesis de la ideología metafísica y estética de Joan Maragall, ya que, como dice Querol al final de su comentario, está construida a partir de los cuatro puntos principales de la doctrina maragalliana:

1. Actitud contemplativa: Maragall considera que la experiencia estética está causada por la captación pasiva de la belleza del mundo. El poeta, arrebatado por esta belleza, siente la necesidad de expresarla.

2. Realismo: aquello que impresiona al poeta es la realidad del mundo, captada por los sentidos. Es por ello por lo que Maragall dice "El arte humano no ha de ir de lo ideal a lo real, sino al contrario. Yo creo que la sana obra de arte es engendrada en una impresión de la realidad". Así pues, "en Maragall la realidad es la madre de la poesía"8.

3. Humanismo: Tras afirmar la belleza del mundo, el poeta reconoce estar celoso de sus ojos y teme la muerte porque le va a privar de este goce "sensitivo". La gran duda existencial del

3. Acerca del modo en que Querol entendía la obra de arte y el proceso de creación artístico resulta especialmente interesante el artículo "La creación artística y lo humano en el arte", en Revista de ideas estéticas, 69 (1960), pp. 13-29. Buena parte de estas ideas aparecen ya apuntadas años atrás en el artículo "Lo humano en el arte", en Diario de Barcelona, 23 de julio de 1950, p. 21.

4. Cant espiritual. Poema vocal a 4 veus mixtes. Música Miguel Querol. Letra Joan Maragall. Barcelona: J. M. Parés, 1952.

5. Esta obra suele aparecer fechada en 1951, pero tanto en la edición impresa de la partitura como en el programa de mano del estreno de la obra aparecen 1947-1951 como los años en los que QuEROL estuvo trabajando en su composición. Su estreno se realizó en un concierto dedicado a las obras de Querol el día 18 de marzo de 1952 en la Sala Vila Arrufat de la Casa Bartomeu (Primera audició de cançons, madrigals i poemes vocals del mestre Miquel Querol Gavaldà, interpretado por el Cuarteto Filharmonía). En este programa aparecen dos composiciones más de QuEROL con textos de Joan Maragall: La vaca cega (19471951) e Intermezzo (1949), ambos también a cuatro voces mixtas.

6. M. Querol: "La estética de Maragall", op.cit., p. 167.

7. Un aspecto muy importante de este punto es la negación del panteísmo que a menudo se ha atribuido a Maragall. Dice QUEROL en su comentario: "[Maragall] es un creyente que al exclamar: 'Señor', bien claro dice su confesión de un Dios personal, diferente del mundo y Creador del mismo mundo. Que nadie, pues, lo acuse de panteísta" (p. 168). En efecto, en su exégesis del pensamiento maragalliano puede extraerse que Maragall entiende el mundo como natura naturata que refleja a Dios en su creación. Esto aparece en el poema más adelante (vv. 39-40) "Tot el que veig se vos assembla en mi... / Deixeu-me creure, doncs, que sou aquí'”.

8. M. QUEROL: “La estética de Maragall”, op.cit., p. 144. 
poeta aparece cuando se llega a plantear si el mantener "eternamente" estos momentos de goce (que es lo que él desea) equivale a la muerte, ya que esto significaría vivir en una ilusión. De todos modos, el poeta disipa estas dudas afirmando que son producto de su débil condición humana y mantiene su fe creyendo que Dios está presente en el mundo a través de su belleza. Así pues, el poeta asume su naturaleza humana, con su doble vertiente: sus limitaciones y su grandeza de poder captar la belleza del mundo a través de los sentidos. Dice Querol: "Y este mundo que ve Maragall asomada su alma a sus sentidos, ¿cómo lo ve que tanto le arrebata? Lo ve en la imperturbable belleza de su simple realidad percibida por la naturaleza humana"'.

4. Optimismo: Finalmente, el poeta pide a Dios que le abra unos “ojos más grandes" para poder contemplar su rostro y así que la muerte sea otro nacimiento.

\section{Elección del poema}

De entrada podemos preguntarnos por qué Querol se sintió atraído por este poema, ya que él mismo critica su contenido por considerar que desde un punto de vista verdaderamente cristiano la postura de Maragall es demasiado mundana al estar tan apegada a lo sensible. En palabras de Querol:

"Como cristianos creemos que la fe y la esperanza sobrenaturales sobrepasan de mucho la medida humana y en consecuencia nuestra fe y nuestra esperanza, en cuanto a su objeto, no pueden pararse aquí, sino que anhelan hacia otro mundo más bello y mejor que el presente. El mismo reparo hacemos respecto a su realismo. Es un realismo sano y lleno de luz, pero demasiado apegado al orden de lo sensible" ${ }^{\prime \prime}$.

No obstante, hay una gran relación entre el tema de esta obra y el pensamiento de Querol. El fundamento principal de la teoría estética de Querol es la búsqueda de un contenido humano en la obra de arte: considera que la causa de que el arte contemporáneo no llegue al público es su carácter deshumanizado, más preocupado en novedades experimentales que no en buscar un contenido humano a la obra. Dice Querol al principio de su artículo "Lo humano en el arte":

"Sucede con frecuencia que la música moderna no satisface las ansias espirituales del que va a un concierto a 'sentir' música. [...] Pero, ¿por qué determinadas obras no gustan? [...] Para mí, la razón de la insatisfacción de tantas obras de arte es porque en ellas está ausente 'lo humano"'11.

Para justificar esta postura, Querol echa mano del pensamiento humanista de Maragall y en especial de su concepto de belleza transhumanada, es decir, manifestada y expresada a través del hombre. En palabras de Querol:

9. Ibid., p. 141.

10. Ibid., p. 171, nota 60.

11. Recordemos que este artículo es del año 1950, en plena efervescencia de experimentación musical. 
"Escribía Maragall en la carta IV a Carlos Rahola: "jo allá on trobo l’home visc fortament". Pues bien, estas obras a que nos referimos no las vivimos fuertemente, no nos dicen nada, porque en ellas no encontramos al hombre; y la consecuencia puede ser gravísima, puede ser que no sean siquiera obras de arte, sino tan sólo experimentos físico-auditivos, pues si el Arte es, según el mismo Maragall y otros, "la belleza transhumanada", es decir, manifestada y expresada a través del hombre, estas obras en cuestión no son obras de arte, puesto que unas veces se manifiestan a través del cerebro sólo, otras, mediante la pura sensación auditiva, otras, en aras de la pura sentimentalidad [...], mas en ninguno de estos casos se manifiesta a través del hombre; mientras que una conquista definitiva de la filosofía estética moderna asegura que la obra artística es, por antonomasia, el producto del hombre íntegro, de su inteligencia, de su corazón, de sus sentidos, de sus nervios y hasta del ambiente que le envuelve; de todo ello simultáneamente, en indisoluble unidad"12.

De hecho, añade Querol de un modo categórico: "Revelar la humana visión del mundo: tal es el sentido del arte y lo que a Maragall interesa de los demás artistas"13.

Por otra parte, el tema principal de este poema también guarda una gran relación con el pensamiento de Maragall desde el punto de vista de la actitud contemplativa ante la realidad para concebir la obra artística. Querol, de un modo muy similar al de Maragall, considera que la inspiración surge de una actitud contemplativa en la que el artista siente la necesidad interior de expresar la visión de la belleza con los medios propios de su arte. Escribe Querol:

"La cantidad de la fuerza emotiva no guarda relación con el grado de belleza de la obra bella; es más, una emoción demasiado fuerte puede hacer creer al artista en su momento de entusiasmo que la obra vale más de lo que en realidad vale. [...] El mejor grado de emoción es aquel que no desequilibra la actividad de las otras facultades. Todo lo que el artista ve y experimenta, lo ve y experimenta en un estado de serenidad contemplativa, y junto con esta 'visión inicial', como la llama el poeta catalán Joaquín Ruyra, nace el deseo -que el artista lo siente como un imperativo y mandato interior- de expresar aquella visión de belleza con los medios propios de su arte"14.

Es más, Querol utiliza palabras del propio Maragall para describir su modo de entender la experiencia estética:

"El poeta Maragall a este momento psicológico lo llama 'estado de gracia', y lo describe de esta manera: 'Ante la visión de la forma quédase el poeta enamorado de su belleza, y esta visión engendra en el alma humana un profundo anhelo de expresión, de decir lo que ve; entonces, fruto de este anhelo, brota espontáneamente la palabra como encarnación expresiva de esta visión" "15.

Así pues, a pesar de las críticas de Querol acerca de este modo de entender la experiencia estética y la fe, el Cant espiritual de Maragall le proporciona un material de inmensa riqueza para su obra tanto por la búsqueda de contenido humano como por el modo de plantear la relación del hombre con la belleza del mundo y de Dios. Incluso se podría decir, de un modo más poético, que el Cant espiri-

12. Ibid., p. 139.

13. Ibid.

14. M. QueRoL: "Lo humano en el arte”, op.cit., p. 16, subrayado mío.

15. Ibid. pp. 16-17, subrayado mío. 
tual de Maragall tiene sobre Querol un efecto similar al que la belleza del mundo produce en el poeta, y Querol, consciente de ello, necesita plasmar esta belleza del mundo captada por Maragall a través de su música.

A pesar de esto, esta búsqueda de contenido contradice la idea de Querol -apoyada de nuevo en el pensamiento de Maragall- según la cual no suelen darse buenas obras musicales con textos de gran calidad literaria ${ }^{16}$. No obstante, parece que en esta ocasión a Querol le motiva más el sentido del texto que no la música en sí: la música brota del contenido profundo del poema y se adapta a las palabras para favorecer su comprensión; y es por esto por lo que Querol concibe esta obra como poema musical al buscar una representación lo más respetuosa posible de las ideas del texto.

\section{Estilo musical del Cant espiritual}

El estilo musical con el que Querol plasma el contenido del Cant espiritual parte de una asimilación de la tradición: Querol parte de un estilo tradicionalista, aunque juega con elementos de la armonía tradicional para darle un nuevo sentido, sobre todo cuando el significado del texto lo requiere. De hecho, Querol considera que lo verdaderamente importante no es tanto buscar algo totalmente original, sino más bien asimilar lo anterior para que el artista pueda expresarse a sí mismo. En palabras de Querol:

"El genio se asimila las ideas de los demás y las convierte en sustancia propia. Escribe de su propia sustancia y no se preocupa sino en traducirse y expresarse a sí mismo exactamente. [...] El que se engañe, el que queriendo plasmar su personalidad en la obra de arte resulta que ha cometido un plagio de consideración, debe retirarse de la vida de artista creador, porque es señal de que no tiene vida propia y original"17.

Esta crítica a la originalidad a ultranza es muy cercana al pensamiento de Maragall, dada la importancia que éste le da a la tradición -poesía popular-. Maragall opina que la sencillez de la poesía popular es la más cercana a la poesía pura porque surge de una verdadera necesidad de expresión del pueblo -no entendido como masa, sino como unión de diversas individualidades- ${ }^{18}$. Además, según Maragall la imitación artística es una buena manera de eliminar lo superfluo de la obra original para depurarla, mostrando así al autor de un modo más verdadero. Dice Querol:

16. Dice Querol, "la comprobación de este hecho que los musicólogos vemos confirmado a cada paso en el estudio de los cancioneros musicales, hace decir a Maragall que "la situación de inferioridad de la poesía en unión con la música parece ser una especie de ley de estética artística" (M. Querol: "La estética musical de Juan Maragall (1860-1911)", op.cit., p. 173). Sobre esto, resulta muy curioso observar cómo Querol y Maragall coinciden en decir que el paradigma (discutible) de un obra musical extraordinaria forjada sobre un libreto pésimo es el Don Giovanni de Mozart/Da Ponte. Querol explica este punto de vista de Maragall en "La creación artística y lo humano en el arte", op.cit., p. 23, y muestra sus propias ideas en: Miguel Querol: "Don Juan en la ópera. 'El Burlador' en manos de Da Ponte", en Diario de Barcelona, 15 de enero de 1949, p. 3; y también en Miguel Querol: "Don Juan en la ópera. El Burlador y 'un espíritu burlón””, en Diario de Barcelona, 25 de febrero de 1949 , p. 3.

17. M. Querol: "La creación artística y lo humano en el arte”, en Revista de ideas estéticas, 69 (1960), p. 23.

18. "[Maragall] muy lógicamente recomienda la poesía popular como la mejor escuela de poesía, porque el pueblo nunca canta por vanidad, sino únicamente por necesidad de expresión” (M. QUEROL: "La estética de Maragall”, op.cit., p. 152). 
"El artista debe aprender a ser paciente y esperar el momento henchido de realidad viva. Pero Maragall [...] recomienda la imitación artística (acto positivo de voluntad) como manifestación de la solidaridad secular de la cultura humana y como antídoto contra la manía de originalidad absoluta. [...] El que imita la obra atiende principalmente al oro y limpia de escorias la obra imitada en la suya. Al no tener la pretensión de crear, cobra con la humildad imitadora una graciosa libertad y confianza que le deja hablar con más pura inspiración y mostrarse, por tanto, más poético y personal que de ninguna otra manera. Y es que el poeta está entonces en su justa condición de hombre entre hombres que se van pasando de uno a otro la divina antorcha, avivando cada uno la llama en el propio aliento. Así, pues, toda obra de arte contiene un período o proceso temporal de purificación estética; tal es el secreto de la poesía popular"19.

Otro elemento que caracteriza el estilo de esta obra es el ritmo, que mantiene la prosodia del texto y que fluctúa cambiando según sus necesidades. De hecho, el ritmo es precisamente uno de los conceptos más importantes en la doctrina estética de Maragall. Según él, el poeta, mediante la "palabra viva", debe ser capaz de descubrir el ritmo de lo concreto que late bajo el velo de lo aparente; y este ritmo debe entenderse como una manifestación esencial de la vida cósmica: "Su crear consiste en alzar, mediante la 'palabra viva', el velo de lo aparente y descubrir el ritmo esencial de lo concreto. Esta visión de la realidad afecta a todos los órdenes de la vida cósmica y de la específicamente humana" ${ }^{20}$. Dice Maragall: "la poesía ha de ser el ritmo de la creación vibrando a través de la tierra en la palabra humana"21. Querol considera que Maragall cumple este objetivo: "Maragall es un formidable desentrañador del ritmo de la vida universal hecho patente en otros ritmos humanos que transparenta el artista verdadero" 22 . Así pues, podemos pensar que estas ideas maragallianas acerca de la importancia del ritmo en la poesía pudo llevar a Querol a optar por un ritmo fluido, prosódico y muy "textual" para respetar el ritmo original de la poesía de Maragall, reflejo del ritmo que subyace bajo las apariencias.

\section{Representaciones musicales de ideas del texto}

Por último, queda por ver cómo Querol representó musicalmente las ideas más profundas del texto de Maragall. De entrada, podemos decir que la obra se estructura a partir de momentos de tensión y distensión (tonalidad tratada de un modo tradicional, basada en acordes tríadas y cuatríadas de dominante y sensible contrapuesta con modulaciones, sobre todo cromáticas), lo cual podría representar el paso de la belleza arrebatadora del mundo, las dudas existenciales del poeta acerca de su fe y la esperanza. En este sentido, la tonalidad de Re mayor es la principal de la obra y la que simbolizaría la belleza del mundo, reflejo de la belleza de Dios. Los primeros compases constituyen un tema en Re mayor que crea una atmósfera plácida que representa la belleza del mundo: Si el món ja és tan formós, Senyor, si es mira amb la pau vostra dintre de l'ull nostre, què més ens podeu donà en una altra vida? Querol opta por repetir esta frase para darle mayor énfasis. Este tema vuelve a aparecer más adelante (cc. 102-109) con

19. M. Querol: "La estética de Maragall”, op.cit., p. 163.

20. Ibid., p. 143.

21. Ibid., p. 155.

22. Ibid., p. 139. 
unos versos que retoman el sentido de los primeros: Si heu fet les coses a mos ulls tan belles, / si heu fet mos ulls $i$ mos sentits per elles, / per què acluca'ls cercant...? Aparte de esta breve referencia interna a la obra, en general, la música se centra en un continuo devenir sin una melodía dominante, dado que la obra está articulada de un modo mayoritariamente homofónico en que cada voz tiene la misma importancia por el hecho de formar parte del todo armónico.

Si la belleza del mundo está representada por la claridad de la tonalidad de Re mayor, Querol juega mucho con tenebrismos causados por cromatismos y por modulaciones a otras tonalidades, sobre todo menores (Fa menor, Si menor, Mi menor, incluso Re menor, etc.). Un caso claro de utilización de cromatismos modulantes para representar una idea del texto aparece en la palabra "mort" (cc. 19-26), terminando en una tríada perfecta mayor con sol\# como fundamental que crea un acorde que está a distancia de tritono de la tonalidad de $\operatorname{Re}$ mayor $(\mathbf{E j} \mathbf{j} \mathbf{1})$.
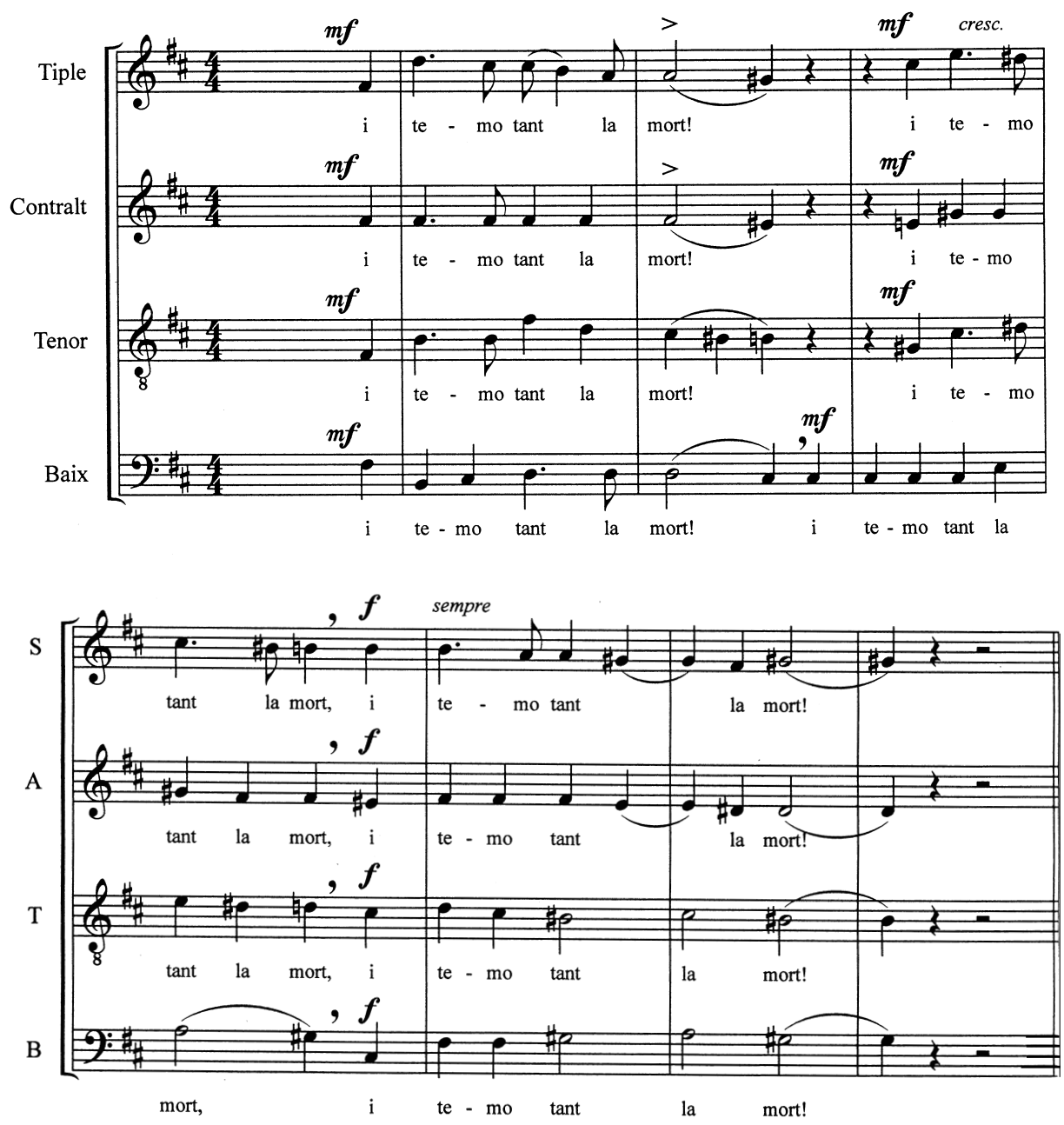

Ej. 1: Miquel Querol, Cant espiritual, cc. 19-26: representación musical del temor a la muerte (“I temo tant la mort!!"). 
En el centro se halla un verdadero punto de inflexión con un cambio de estilo (declamat y recitat lliure en la partitura, cc. 57-59) en los versos en los que el poeta se plantea las dudas existenciales más peligrosas para su fe: $O$ és que aquest fe etern és ja la mort? Mes llavores, la vida, què seria? Fóra l'ombra només del temps que passa, la il.lusió del lluny i de l'aprop, i el compte de lo molt, i el poc, $i$ el massa, enganyador, perquè ja tot ho és tot? El declamado y recitado enfatizan el sentido de los versos con un estilo más cercano al habla y por tanto a aquello mundano. En estos compases no sólo tambalea la fe del poeta, sino que también tambalea el estilo de toda la obra. No obstante, Querol vuelve triunfalmente al estilo anterior con las palabras Tant se val, tan se val!, pasando además de Mi menor a La mayor.

Tras esto, la parte esencialmente humana del poema viene representada por un mayor juego entre las voces. Resulta especialmente relevante el modo en que Querol utiliza la melodía de los bajos para musicar los versos en que Maragall pone de manifiesto la aceptación de su débil condición humana (Home só i és humana ma mesura, per tot, per tot quant puga creure i esperar; si ma fe i ma esperança aquí s'atura, me’n fareu culpa més en enllà?, cc. 80-95). Para ello Querol compone una melodía sencilla pero con la siguiente acotación: "Canti el baix com un violoncel solista, acompanyant-lo les altres veus". Se trata de una de las poquísimas ocasiones en que la melodía se centra de un modo tan claro en una sola voz, y resulta significativo el hecho de haber escogido para ello la voz de Bajo, justamente la más humana y la más apegada a aquello material ${ }^{23}(\mathbf{E j} \mathbf{2})$.

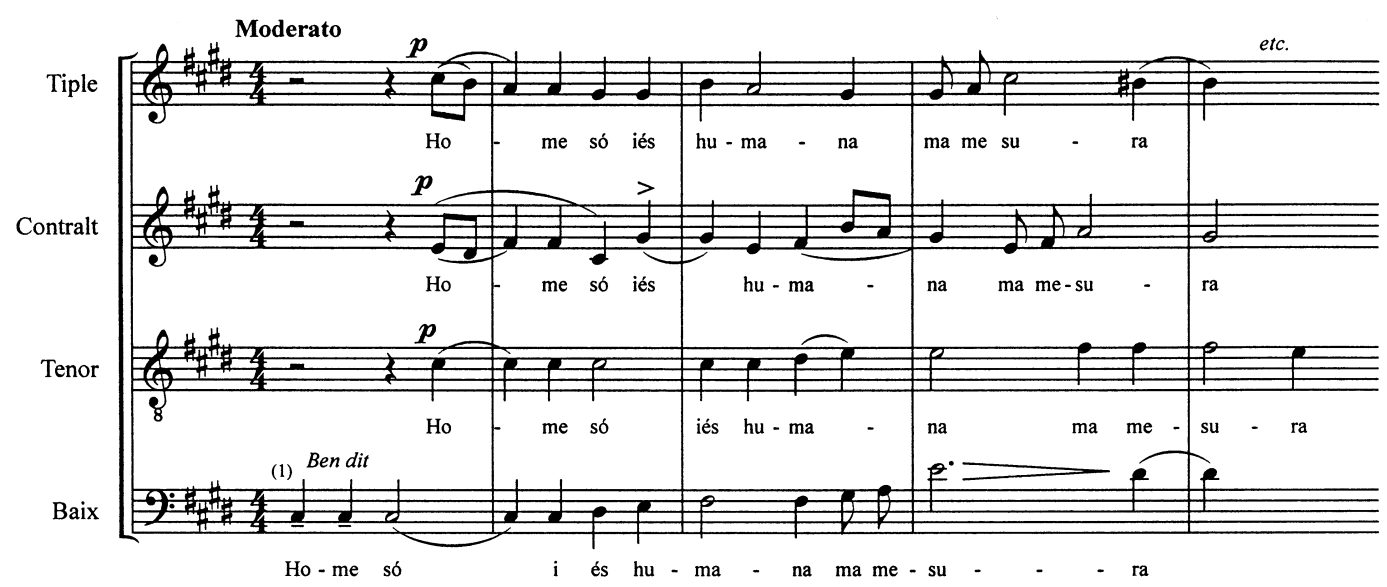

(1) Canti el baix com un violoncel solista, acompanyant-lo les altres veus.

Ej. 2: Miquel Querol, Cant espiritual, cc. 80-84: representación musical de la naturaleza humana ("Home só i humana és ma mesura")

23. En la historia de la música se puede observar una cierta tendencia a identificar lo grave con lo material y lo agudo con lo más divino. Este hecho se pone de manifiesto, por ejemplo, en la elección de voces en las Pasiones: Bach escoge la voz de Barítono para representar a Jesucristo en su lado más humano. Por otra parte, el hecho de considerar la musicalidad de este pasaje como "un violonchelo solista" ayuda mucho a imaginarnos su sonoridad, grave y con melancolía. No obstante, resulta curioso que justamente el violonchelo haya sido un instrumento a menudo identificado con Jesús como Hijo. Por ejemplo, la compositora 
Por último, la obra finaliza con una sección de carácter más contrapuntístico que va desembocando en un re en ppp, el cual, en cierto modo, puede representar una depuración de la tríada inicial en Re mayor para mostrar la idea de esperanza en un nuevo nacimiento tras la muerte.

\section{Conclusiones}

Hemos visto, pues, cómo en el Cant espiritual confluyen las ideas de Maragall y de Querol sobre el arte y la condición humana. Si bien Querol hace suyas muchas citas de Maragall para explicar su pensamiento estético, en el Cant espiritual Querol logra hacer una verdadera síntesis del pensamiento y estilo de ambos autores a partir de un conocimiento profundo del contenido del poema y de un gran respeto y admiración por el pensamiento estético de Maragall. Así pues, en lo concerniente a Maragall, Querol amplía la relación entre literatura y música a una profunda reflexión acerca de una determinada concepción de la obra de arte, de la capacidad creativa del hombre y del ser humano en sí.

Sofía Gubaidulina lo metaforiza de este modo en sus Siete Palabras. Vid. Valentina Cholopova: "Sofija Gubajdulina. Tra Oriente e Occidente", en (Enzo Restagno, ed.) Gubajdulina. Turín, EDT, 1991, p. 183; y Aurelia Pesarrodona: Música de temàtica cristiana a Europa (1945-2000). Barcelona, Editorial Claret, 2004, que parte del trabajo "L'expressió del sentiment cristià a la música contemporània", realizado con una beca de la Fundación Joan Maragall, Barcelona (inédito). 